\title{
LA TEORÍA DE LAS SIBILANTES PROPUESTA POR RUFINO JOSÉ CUERVO: NOVENTA AÑOS DE DISCUSIONES*
}

Los años 1895 y 1896 marcan, en su conjunto, una fecha doblemente notable en los anales de la filología hispánica, por haber coincidido en ella la publicación de un libro importante de un investigador todavía joven con la de un artículo no particularmente largo, pero sí muy nutrido y firmado por un especialista ya reconocido por todas partes como verdadero maestro. El erudito joven en cuestión era Ramón Menéndez Pidal, y el trabajo a que acabo de aludir fue la primera redacción de una monografía que llegó a ser famosa, La leyenda de los Infantes de Lara, acogida con excepcional generosidad por el mejor crítico europeo de aquella época, Gaston Paris ${ }^{1}$. En cuanto al artículo - ya descrito, pero

* Este artículo encierra el texto de la ponencia que presenté, por invitación, en el Primer Congreso Internacional sobre el español de América (Puerto Rico, 1982). En un principio, el estudio estaba para figurar en las Actas de dicho congreso (las cuales, por desgracia, no llegaron a publicarse). En ese ínterin, me he ocupado repetidas veces en las peripecias de las sibilantes españolas; basta con mencionar dos trabajos, de fecha reciente, que están para salir a mediados o, a más tardar, a fines de 1987: a) "Regular sound development, phonosymbolic orchestration, disambiguation of homonyms", Actas de la Berkeley Conference on Sound Symbolism (1986); y b) "Integration of phono-symbolism with other categories of language change", Actas de la Seventh Conference for Historical Linguistics (Pavia).

${ }^{1}$ El valioso glosario anotado que acompañaba la edición original de Los Infantes de Lara quizás sea la primera muestra de la curiosidad del autor por problemas de lingüística histórica - interés todavía secundario en aquel entonces, que iba cristalizando paulatinamente. El primer libro de gran envergadura de Menéndez Pidal (1892) versaba sobre las crónicas. Con motivo de la publicación (no llevada a cabo, por desgracia) de sus Obras completas, el autor hizo varios agregados a Los Infantes de Lara, revisando también el glosario. 
todavía no identificado-, fue la primera parte de las Disquisiciones de Rufino José Cuervo, la cual salió en una erudita revista parisiense recién fundada y que ya gozaba de un éxito sensacional, la famosa Revue Hispanique, lanzada no por un instituto universitario o una sociedad de especialistas, como era $-\mathrm{y}$ sigue siendo- la norma, sino por un individuo de carácter independiente, para no decir rebelde o terco, Raymond Foulché-Delbosc. La carrera sin par de Menéndez Pidal constituye un apasionante tema aparte, en que hoy no podemos ahondar; pero las Disquisiciones de Cuervo - mejor dicho, ciertas páginas de la primera parte de aquel estudio - sí merecen una atención detenida dentro del marco de este Congreso, no sólo por los felices hallazgos concretos que encierran y el método ejemplar seguido por el ilustre filólogo colombiano radicado en París, sino también - y ante todopor las extraordinarias reverberaciones que provocaron a lo largo de un cuarto de siglo, de ambos lados del Atlántico. Representan el primer caso de la enérgica intervención de Hispanoamérica en el desarrollo de la lingüística románica, disciplina hasta entonces casi exclusivamente europea.

Cuando Foulché-Delbosc quien ya andaba reñido con el "Establishment" universitario francés allá por 1894 (fecha de la fundación de su revista) comenzó a buscar colaboradores prestigiosos para la Revue Hispanique, nada más natural en tales circunstancias que dirigirse a un individuo de nacionalidad extranjera e impecable reputación científica, a quien se le veía todos los días tomando notas en la Bibliothèque Nationale de la capital de Francia. Pero Cuervo, a quien le repugnaba cualquier trabajo superficial, apresurado, si bien - como me imagino- no tardó en aceptar la invitación en principio con toda cortesía, de hecho reaccionó con característica lentitud; por último ofreció a Foulché-Delbosc un manuscrito muy pulido en su redacción, espléndidamente documentado y, ante todo, basado en un examen verdaderamente riguroso del material - lo mejor que se podía llevar a cabo en aquel entonces ${ }^{2}$.

Examinemos, pues, pormenorizadamente la pesquisa que está sobre el tapete de juicio. El título exacto, algo largo para el gusto moderno, es "Disquisiciones sobre antigua ortografía y pronunciación castellana" y ocupa en la revista ciento cinco páginas; es decir,

${ }^{2}$ Sobre las relaciones epistolares y personales entre estos dos individuos se pueden sacar ciertas conclusiones interesantes del carteo que salió a luz en 1977. 
casi equivale a un libro delgado. La primera parte, la que corresponde al año 1895, salió en el tomo segundo de la Revue Hispanique, extendiéndose desde la primera página de dicho tomo, todavía bastante delgado, hasta la 69, y absolutamente nada indica que se trata tan sólo de una primera parte, de un trozo por definición incompleto: ni el índice general de materias, ni el título, ni la última página despiertan el más mínimo apetito por lo que ha de seguir. Con gran sorpresa, no cabe duda, de varios lectores que se fijan en parecidos detalles, el autor publicó, al cabo de tres años, en la misma revista, un agregado que llamó "segunda parte", el cual abarca sólo 36 páginas (272-307); a título de apéndice, suplemento o excursus, siguen seis páginas más dedicadas a un problema más bien de literatura que de filología o lingüística, girando en torno a la Diana de Jorge de Montemayor - digresión que no puede dejar de producir un anticlímax, dada la flojedad del enlace. La segunda parte encierra, pues, una elaboración espontánea, no prevista por el autor en un principio 3 .

¿Cuáles son los problemas que Cuervo acometió en este trabajo - para acudir a un inmejorable giro francés- "de longue haleine"? La primera parte, que toma como punto de partida dos tratados clásicos del propio Nebrija (pp. 1-4), se divide en cuatro elementos bastante independientes: unas secciones relativamente breves sobre la $B$ y la $V$ (pp. 5-15), sobre la $S$ y la $S S$ (pp. 48-52) y sobre el uso de $X J G H$ (pp. 49-69), quedando aparte una sección mucho mejor desarrollada sobre dos consonantes africadas del español antiguo, la $\xi$ y la $z$, problema sumamente espinoso al que Cuervo no vaciló en dedicar treinta y cuatro páginas muy

${ }^{3}$ La palabra "disquisiciones" - por cierto, no muy común en españolse ha empleado repetidas veces en lo relativo a las indagaciones de Cuervo, lo cual ha terminado por complicar el aspecto bibliográfico del asunto que nos ocupa. Así ambas partes de la primera versión (la de 1895-98) así como la segunda versión, póstuma, que discutiremos más adelante, han sido reimpresas con todo primor tipográfico y con aparato crítico en el t. 2 de las Obras de RuFINo José Guervo (Bogotá, 1954), bajo la dirección de Rafael Torres Quintero, correspondiendo a las pp. 240-476 de dicho tomo; no deja de ser lamentable que una sección mucho más extensa del tomo -a saber, las pp. 9-835, que abarcan otros varios estudios - lleve un título peligrosamente parecido: "Disquisiciones sobre filología castellana"'. Como si no bastase con esta confusión, existen aparte colecciones o selecciones póstumas de escritos en clave didáctica o histórica del mismo protagonista de la filología colombiana, con títulos muy semejantes, y alguna que otra de ellas contiene las Disquisiciones del último decenio del siglo pasado a que me refiero, particularmente, en el trabajo presente. Para todos los detalles, véase el apéndice bibliográfico. 
apretadas (15-48). En el fondo, se trataba siempre en este primer conjunto de estudios de las peripecias de fonemas o grafemas aislados. A la inversa, la segunda parte (es decir, la de 1898), enfocaba exclusivamente grupos o nexos de consonantes en posición media, limitándose por añadidura a cultismos y semicultismos. El propio Cuervo definió así su programa de indagación para este segmento, por decirlo así, supernumerario:

Me propongo especialmente tratar aquí de la lucha que desde tiempos remotos han sostenido la lengua popular y la lengua literaria con respecto a la pronunciación y ortografía de voces que ofrecen ciertas combinaciones de consonantes y que se tomaron del latín cuando ya dejaron de obrar las leyes fonéticas que transformaron tales combinaciones en el caudal primitivo del castellano.

Lo que se saca en limpio de tal deslinde es que Cuervo, para la Parte Segunda, no necesitaba etimologizar escrupulosamente cada eslabón de las cadenas léxicas que reconstruía.

Huelga decir que para el pequeño grupo de especialistas que seguían las actividades de Cuervo con interés marcado, en las Américas igual que en Europa, todas las divisiones y subdivisiones de su nueva monografía tenían gran importancia. A principios y mediados de los años noventa el erudito colombiano ya era una figura destacada. Tenía unos cincuenta años, llevando veinte a Raymond Foulché-Delbosc; era hijo de un padre ilustre y autor de tres libros que habían despertado mucha curiosidad y, por lo demás, no se vendían mal, a juzgar por la rapidez con que se sucedían las ediciones. De su primera obra maestra, las Apuntaciones críticas sobre el lenguaje bogotano, que lanzó a los veintitrés años de edad, es decir, en 1867, en la capital de Colombia, salió una segunda edición, "notablemente aumentada", en 1876, y una tercera edición, sencillamente "aumentada', las dos impresas también en Bogotá; además, una cuarta, que lleva la fecha de 1885, esta vez ya impresa en Francia, si bien todavía no en París. De la obra monumental del autor, el Diccionario de construcción y régimen de la lengua castellana, se distribuyó una muestra de 160 páginas en 1884 , desde París, y el primer tomo entero, que corresponde a las letras A y B, a los dos años. El segundo tomo, que abarca las letras C, $\mathrm{CH}$ y D (a decir verdad, con atención mínima prestada a la $\mathrm{CH}$ ), estaba de venta en 1893; es decir, su publicación se coloca entre la de la primera parte y la de la segunda de las Disquisiciones tantas veces aludidas. Finalmente, allá por 1892 ya salió la cuarta 
edición de la Gramática de Andrés Bello con las "extensas notas", para nada decir del índice alfabético, que se deben a la pluma de Cuervo. Este pequeño inventario, que se ciñe a los libros del filólogo colombiano domiciliado en París, haciendo caso omiso de sus artículos, demuestra la estima de que gozaba en varios ambientes y puede servir de garantía de que ningún estudio que publicaba podía dejar indiferente determinado círculo de lectores dotados de la inteligencia y curiosidad imprescindibles para disfrutar de tales lecturas o consultas. Sin embargo, no hay duda de que un solo capítulo de la nueva monografía, a saber, las treinta páginas - austeras y concentradas- que dedicó a las consonantes sibilantes africadas, la $\zeta$ y la $z$, tuvo en seguida varias repercusiones en parte muy notables, a cuyo conjunto no sería exagerado llamar "El gran debate sobre las sibilantes del español antiguo". Queda por explicar, entonces, por qué este capítulo particular logró -inmediata y, al parecer, fácilmente- eclipsar el resto de una obra, por lo demás, muy equilibrada.

Creo que tal desnivel de atención se explica sin dificultad. La mayor parte de los problemas seleccionados por Cuervo para un examen minucioso eran altamente relevantes (como se diría hoy) para un hispanista en el sentido estrecho de la palabra, eso sí, pero encerraban escaso interés para el romanista que cultivaba, ante todo, ora el comparatismo, ora el estudio avanzado de otro idioma congénere, por ej. del francés antiguo, del provenzal o del italiano. Ahora bien: la gran mayoría de los romanistas europeos de aquella época no se dedicaban a investigaciones luso-hispánicas, que por un motivo u otro no estaban de moda en aquel entonces. Dicho de otro modo: problemas muy parecidos a aquellos que planteó Cuervo en lo que atañe al origen y al subsiguiente desarrollo de las $\zeta$ y $z$ españolas medievales ya habían ido preocupando a varios romanistas - en parte de gran talla - de especialización afín pero no idéntica. Esos provenzalistas, italianistas, etc. desde hace largo tiempo echaban de menos un examen pormenorizado del material español, y Cuervo, quizás sin anticipar resonancia tan fuerte, les ofreció, en un momento sumamente oportuno, la exacta cuota de conocimientos e interpretaciones que les hacía falta. De ahí la reacción sin par en los anales de la filología hispanoamericana.

Rayaría en lo pedante si yo me empeñase en reconstruir aquí, prestando atención a todos los detalles, el preludio aludido, el cual ocupa unos tres decenios de labor muy concentrada, que llevaron a cabo representantes de varias culturas y escuelas de pensamien- 
to filológico. Me ceñiré, pues, a lo esencial y lo que da particular relieve a la intervención de Cuervo en los años noventa ${ }^{4}$.

Como pasa casi siempre en los anales de nuestra disciplina, es imprescindible comenzar con la obra de Friedrich Diez; específicamente con el primer tomo, dedicado a la fonética histórica, de su monumental gramática comparada. Ese tomo, en su edición original, salió hace un siglo y medio, y se caracteriza por la selección de una perspectiva muy peculiar: el autor invita a sus lectores a seguir el desarrollo de cada fonema (o, como se expresaba Diez con cierta torpeza, de cada letra del alfabeto latino), a través de los siglos en las principales lenguas neolatinas. Así, en las páginas reservadas para las peripecias post-clásicas de la velar sorda, escrita $\mathrm{C}$ y pronunciada / $\mathrm{k}$ / en un principio, el autor no puede menos de dedicar algunas líneas a la $\mathrm{C}$ española. Pero ya a partir de la segunda edición, ampliamente revisada, del tomo en cuestión, que corresponde al año 1856, se produjo un cambio radical: sin abandonar esta primera perspectiva, Diez le agregó, a título de complemento y corrección, la opuesta, que parte de los sonidos medievales y modernos del romance - ante todo aquellos que encierran una innovación, un desvío del canon clásicoy aspira a identificar sus fuentes o prototipos lejanos. En ambas proyecciones, Diez operaba no sólo con el latín, sino - si bien en escala muy reducida - también con el árabe y los idiomas paleogermánicos. La tercera edición del libro, que cayó en el año 1870, fue la última elaborada por el autor, ya setentón en aquel entonces; las dos ediciones subsiguientes, ambas póstumas, vuelven a ofrecer, sin ampliarlo, el texto de la tercera. En resumidas cuentas, Diez legó a sus sucesores la técnica de la doble perspectiva ${ }^{5}$. Lo curioso es que casi todos se decidieron en favor de la primera; la gran originalidad de Cuervo - mejor dicho, una de sus desta-

${ }^{4}$ Así, hago caso omiso del folleto de Monaci, por no tenerlo presente; y no me detengo en la discusión de las gramáticas históricas de Múgica, Alemany Bolufer, Keller, Gorra y Wiggers, por haber ejercido poco influjo como consecuencia de su escasa originalidad. Registro los datos bibliográficos en el Suplemento, por si alguien se decide a rastrear tales fuentes de interés secundario.

5 No me ocupé más detenidamente de este cambio en el enfoque de DiEz en el trabajo "A Tentative Typology of Romance Historical Grammars" que salió en una revista europea en 1960 y, en forma algo retocada, forma parte de la miscelánea Essays on Linguistic Themes (Oxford, 1968), pp. 71-164, por la sencilla razón de que no tenía a la vista todavía la rarísima segunda edición de la gramática. Más tarde descubrí un ejemplar en la Widener Library de Harvard University. 
cadas originalidades - arraiga, precisamente, en su exclusiva preferencia por la segunda.

Sería interesante sacar en limpio el pensamiento de Hugo Schuchardt - otra figura notable - cuando, de principiante casi, se lanzó en la indagación de la fonética del latín vulgar, regionalmente diferenciado (o, por lo menos, matizado). Por desgracia, el joven autor, algo caprichoso, no avanzó más allá de las vocales en su obra fundamental, Der Vokalismus des Vulgärlateins (1866-68), de manera que sería meterse en puras conjeturas atreverse a discutir cómo se imaginaba entonces el desarrollo de las velares asibiladas y africadas, aunque sí volvió a ese tema en las postrimerías del siglo XIX.

Con lo cual podemos pasar a sentar que la primera investigación de sesgo netamente monográfico que se ocupó en serio de las fortunas de la $c$ (es decir, /k/) latina fue el estudio de un estudioso francés algo enigmático, Charles Joret, quien en 1874, teniendo cumplidos los treinta y cinco años, publicó un libro de tamaño impresionante, $D u C$ [latin] dans les langues romanes. La envergadura de aquel libro no deja de ser imponente, ante todo para una obra concebida y ejecutada en Francia, país que entonces andaba atrasado en la aplicación del método comparado. En efecto, dentro de un esquema algo complicado, por lo menos un capítulo está dedicado al detenido examen del respectivo desarrollo en romance ${ }^{6}$. Por desgracia, todo lo que hizo constar Joret sobre el español carece de valor, por la sencilla razón de que se basaba enteramente en textos medievales impresos a mediados del siglo XIX, nunca en clave crítica, acudiendo editores y tipógrafos a las idiosincrasias del español de su propio tiempo en lo que concernía a la distribución de la ç y de la $z$. Además, Joret prestó insuficiente atención al testimonio del judeo-español. Estas graves deficiencias del capítulo en cuestión llegaron a ser una importante lección para Cuervo, quien, dos decenios después, para sus propias Disquisiciones, en lo esencial decidió no aprovechar textos publicados por primera vez o reimpresos en el siglo XIX, aunque

${ }^{6}$ La clasificación básica que propuso Joret descansaba en los resultados finales de la $/ \mathrm{k} /$ latina - según tendía a convertirse, en los romances, en $/ \mathrm{g} /$, $/ x /, / \theta /$, etc. - , quedando supeditada a tal consideración el puesto que ocupaba el fonema en las respectivas voces del latín: inicial de palabra, intervocálico, agrupado, etc. Es tal estructura caprichosa lo que más reprochaba A. DARMESTETER al autor en su crítica penetrante del libro (véanse las pp. 380 ss. de su reseña). Huelga decir que con la boga del idearium de los neogramáticos triunfó la perspectiva de Darmesteter, en merma de la de su víctima. 
desistía de la aplicación de igual rigor en la redacción de su Diccionario, proyecto concebido con anterioridad y falto de orientación fonética.

En conjunto, cuantos no podemos animarnos a leer un libro forzosamente anticuado, y no particularmente bien redactado, de más de 350 páginas, como resultó ser el de Joret, podemos dejarnos guiar por la mano de un crítico justiciero, Arsène Darmesteter, quien, en su reseña muy nutrida de veinte páginas, subrayó los numerosos aciertos y hallazgos del autor, producto de la enseñanza de l'École pratique des Hautes Études, ante todo en el análisis de ciertos patois de la Francia septentrional (por ej., del picardo y del normando); pero también reconoció varios errores y deslices y, ante todo, numerosas lagunas, concluyendo así su veredicto: 'L'ouvrage est neuf en divers points. L'auteur n'a pas résolu tout le problème de la gutturale, il l'a du moins beaucoup avan: cé". Es curioso que el director de la prestigiosa revista en que salió esta reseña tan penetrante, a saber Gaston Paris, se distanció algo - en una nota final- del juicio quizás excesivamente severo de su discípulo predilecto. De todos modos, monografía y reseña provocaron, entre sus lectores, el deseo de averiguar más, ya que el tema de ninguna manera quedaba agotado. En cuanto al propio Joret, al parecer se sintió herido y dedicó los cuarenta años que la suerte le deparó vivir y trabajar a asuntos enteramente distintos, como la historia simbólica y alegórica de la rosa en la Antigüedad y la Edad Media; las vicisitudes del helenismo francés; y las relaciones literarias entre Alemania, Inglaterra y Francia en el siglo XVIII. Enseñó en la Universidad ("Académie") de Aix, la cual -que yo sepa- no cultivaba la lingüística en aquel entonces.

La discusión se aceleró y acaloró paulatinamente. En su libro juvenil sobre los dobletes del léxico español, Carolina Michaëlis, en vísperas de sus bodas con un prestigioso historiador de arte portugués y de su subsiguiente traslado de Berlín a Oporto, es decir, en 1876, contribuyó al debate con alguna que otra migaja, ya que su inventario de dobletes descansaba en una infraestructura de fonética histórica. Entre los secuaces directos de Diez conviene mencionar al erudito - casi demasiado erudito- filólogo y polígrafo Cari von Reinhardstoettner, en su calidad de autor de una gramática del portugués, del año 1878, pesadamente historicista; así como al hispanista Paul Förster, otro alemán, autor de una gramática notable del español, concebida en clave netamente diacrónica. Este libro, que salió en 1880, rompió con la 
tradición de Joret y Darmesteter, quienes habían adoptado la primera perspectiva de Diez, tomando como punto de partida un sonido latino y pasando a observar sus peripecias; Förster, al contrario, optó por el segundo método dieziano, partiendo del hecho concreto de la existencia de una $\varsigma$ y una $z$ en español y etimologizando, con limitada pericia, gran número de voces que contenían tales fonemas, o tales letras. Luego, categorizando las ecuaciones etimológicas, estableció un cuadro de las llamadas "fuentes" de las consonantes en cuestión. El catálogo de observaciones sueltas que cuajó así, a base de etimologías en parte harto dudosas, resultó muy tosco. Förster supo aprovechar bien los datos que le proporcionaban Diez y Michaëlis, pero a aquella altura no llegó a tamizar, jerarquizar, reconciliar o integrar los hallazgos dispersos. Ofreció a sus lectores una lista de posibilidades compilada con entusiasmo, eso sí, pero con poco sentido crítico. Sin embargo, de la idea de presentar un conjunto de fuentes para determinados fonemas del español se asieron más tarde Cuervo y, con mayor detenimiento en los detalles, el joven norteamericano Jeremiah D. M. Ford, quien todavía cruzará nuestro sendero.

La etapa siguiente coincide con la publicación - en 1883de un libro entero (la primera monografía después de los tanteos de Joret) dedicado exclusivamente a las vicisitudes románicas de la velar sorda latina. Aunque el autor, Adolf Horning, no llegó a hacer una carrera universitaria y así, al fin de cuentas, tampoco consiguió hacer escuela, su libro, más delgado y escueto que el de Joret, no dejó de ser sensacional y creó el clima intelectual en que, a los pocos años, medró la contrapropuesta de Cuervo. Así aquel libro, titulado $Z u r$ Geschichte des lateinischen $C$ vor $E$ und $I$ (es decir, 'Para la historia de la $C$ latina ante $E$ e $I$ '), merece nuestra atención - aunque no siempre nuestra adhesión incondicional.

El título muestra en seguida que Horning aspiraba a cierta economía; así comenzó por eliminar de su crónica o análisis las peripecias de la $/ \mathrm{k} /$ latina ante $a$ (y, con mayor razón, ante $o$ y $u$ ) en posición inicial; o de la $/ \mathrm{k} /$ agrupada, por ej. seguida de una $t$, en posición interna, etc., reduciendo quizás a un tercio el total de los problemas en cuya solución decidió empeñarse. Vista desde la atalaya de hoy - nos separa un poco más de un siglo de la redacción de ese libro- el propio estudio de Horning y sus fortunas se caracterizan por tres rasgos esenciales, a saber:

a) El autor fue quizás el primer comparatista en nuestro campo quien, a la zaga del ilustre indoeuropeísta danés Carl Verner 
y de sus secuaces inmediatos ${ }^{7}$, atribuyó una enorme importancia a la posición del acento en el desarrollo de los sonidos - tal vez equivocadamente en lo que atañe a las consonantes;

b) Con Horning comienza el fuerte predominio de la preocupación por las vicisitudes del francés (antiguo, moderno y dialectal) en la ciencia centroeuropea. Muy cerca en la escala de valores sigue, de aquí adelante, el italiano, mientras el español y el portugués están condenados a constituir la retaguardia. En efecto, los capítulos del libro en cuestión que versan sobre los dos idiomas de la península ibérica son relativamente flojos, a pesar del esporádico uso - "novedoso" en aquel momento- de la documentación judeo-española contemporánea, y

c) En lugar de una sola reseña - a decir verdad, mortífera en su efecto- como lo fue aquella que dedicó Darmesteter al trabajo de Joret (la otra, más tibia, firmada por C. Chabaneau, contó por poco), esta vez salieron tres reacciones críticas, menos profundas pero mejor equilibradas y casi de igual peso. Es curioso que una de ellas emanaba de un principiante suizo alemánico prácticamente desconocido, un tal Wilhelm Meyer, quien más tarde, contraídas sus nupcias con Fräulein Lübke, había de convertirse en el ilustrísimo Meyer-Lübke; las otras dos, más halagüeñas, llevaban las respectivas firmas de un benemérito filólogo alemán de procedencia y nombre franceses, Hermann Suchier, y de un norteamericano domiciliado en Baltimore, A. Marshall Elliott, el fundador de la escuela filológica de Johns Hopkins. Ensanchándose así y ganando en hondura el cauce de la discusión, el problema de las sibilantes románicas oriundas de la velar sorda latina se transformaba lentamente en una cuestión muy reñida de repercusiones internacionales. Todavía faltaba en el coro la voz de Hispanoamérica.

- Pero la gran novedad que trajeron consigo los años ochenta del siglo pasado no eran sólo nuevos conceptos prosódicos de la gramática histórica, sino, ante todo, una técnica mucho más escrupulosa y mejor desarrollada de reproducir textos medievales. Como era de prever, la innovación cundió de los países de lengua

${ }^{7} \mathrm{El}$ único romanista que se adhirió - precipitadamente- a las ideas de Verner antes de Horning fue - si no me engaño- una figura rara vez evocada hoy día, a saber F. Neumann, en su gramática histórica del francés antiguo (1878). Sobre estos episodios, que ya parecen pertenecer a un pasado remoto, traté de arrojar cierta luz en mi nota (del año 1966) sobre varias aplicaciones poco felices de la Ley de Verner al material románico: véanse en particular las pp. 83-86, dedicadas al vaivén de las hipótesis sobre las sibilantes. 
alemana. He aquí algunos informes concretos: en 1880, un joven desconocido, Gottfried Baist, presentó en una universidad bávara de segunda fila, Erlangen, a título de tesis de doctorado, una edición paleográficamente minuciosa, aunque por cierto no impecable, del Libro de la caza de don Juan Manuel, precedida de un examen de treinta páginas de la clasificación de los manuscritos disponibles para las futuras ediciones críticas del autor medieval. (A los pocos años salió la edición del Libro del caballero y el escudero, preparada por S. Gráfenberg.) El mismo año de 1880 presenció la esmerada publicación de un lapidario redactado en español medieval: Ein altspanisches Steinbuch, texto que se coloca en el cruce de dos tradiciones: la isidoriana y la que se asocia con Marbodio, obispo de Rennes; el responsable por esta hazaña filológica fue Karl Gustav Vollmöller, el fundador de la importante revista Romanische Forschungen así como de un anuario concebido en clave crítica (Jahresbericht über die Fortschritte...). Pasados tres años, un joven suizo alemánico, Heinrich Morf (el futuro sucesor de A. Tobler en Berlín), acometió un problema más arduo: la publicación del Poema de José, en transmisión aljamiada, a base de un manuscrito hispano-arábigo conservado en la Biblioteca Nacional de Madrid. Pronto se adhirió a este grupo Friedrich Lauchert al dar a conocer dos textos medievales, La estoria del Rey Anemur... y La estoria de los quatro dotores de la Santa Eglesia. Esta moda puso fin a la manera desaliñada de entresacar textos de manuscritos medievales, remozándolos caprichosamente en lo ortográfico, tal como habían practicado esa técnica los filólogos facilitonos de la generación de Florencio Janer y Pascual de Gayangos. De aquí en adelante, no podía ser igual a nadie si el manuscrito en cuestión traía una $s$ of simple o doble; si el conista acudía a una $z$ o una $\xi$; etc. $\mathrm{Y}$ así, prestando atención a los detalles paleográficos, los eruditos de la Europa Central y muy pronto otros, que trabajaban en París o en $\mathrm{Madrid}^{8}$, se dieron cuenta de que, en

\footnotetext{
${ }^{8}$ Muy lejos de mí afirmar que, a partir de mediados del siglo xix, España careciera de excelentes paleógrafos-archiveros. Pero ello es que la mayor parte de esos especialistas dedicaba su talento y pericia a la publicación de toda clase de actas y documentos (pienso en primer lugar en tan consumados técnicos como el P. Fidel Fita así como Aureliano Fernández-Guerra y Orbe, de cuya edición del Fuero de Avilés [1865] opinaba RAFAEL LAPESA en 1948: "La llevó a cabo... con esmero notable para lo que entonces se acostumbraba"' [Asturiano y provenzal en el Fuero de Avilés, Acta Salmanticensia, Filosofía y Letras, t. 2, núm. 4, p.7]. Sólo con la edición de las Cantigas alfonsinas que le encomendó al marqués de Valmar la R. Academia Española y con la publi-
} 
español antiguo, se escribía y presumiblemente se decía fazer y redondeza, lo que armonizaba con la grafía y la pronunciación portuguesa; y, además, braço, lo que también concordaba con el canon occidental; pero que tampoco faltaban casos más enrevesados, como el de desmenuzar/esmiuçar, en que el testimonio del español antiguo, restaurada la ortografía e, indirectamente, la pronunciación auténtica, ya no cuadraba bien con el material gallego-portugués ora medieval, ora moderno. Así comenzó a imponerse la necesidad de revisar cuanto se había investigado hasta entonces, esta vez - en la medida de lo posible - a la luz de lecciones impecables; y para esta operación, delicada sin remedio, ya que fácilmente podía herir el pundonor de varios eruditos de la generación vieja, se necesitaba un especialista muy autorizado. Este papel, a mediados de los años noventa, incumbió a Rufino José Cuervo.

Agregando una última pincelada al panorama intelectual que hemos ido reconstruyendo, para mostrar cómo terminó por encajar el opúsculo de Cuervo con lo que se andaba haciendo por aquellos años, conviene mencionar que en 1888 y en 1890 - es decir, casi en vísperas de la publicación de la primera entrega de las Disquisiciones - salieron, respectivamente, el tomo primero de la gran enciclopedia (Grundriss) de Gróber y el tomo dedicado a la fonética de la monumental gramática comparada de W. Meyer-Lübke. El aludido tomo de la enciclopedia - la primera jamás planeada en tal escala por los romanistas - era de sesgo netamente lingüístico, y en él figuraban, a título de secciones semi-autónomas, un esbozo de la gramática histórica redactada por Baist; el correspondiente bosquejo - más circunstanciado- que había preparado Jules Cornu para el gallego-portugués; y, por añadidura, un breve pero jugoso estudio de los antecedentes latinos, escrito por el futuro Meyer-Lübke. Huelga decir que la caprichosa asibilación de la $C$-es decir, de la $/ \mathrm{k} /$ - latina ocupaba un puesto de honor en todos estos contextos y que la fase anterior (o primitiva) del desarrollo (es decir, el propio latín) representaba casi obligatoriamente el punto de partida común, con mayor dogmatismo que en los últimos trabajos de Diez. Como los autores no se ponían de acuerdo, ante todo en ciertos contextos muy característicos en que el español antiguo concedía mayor ámbito a la $z$ sonora que

cación de varios textos de la literatura amena medieval que ejecutó hábilmente A. Paz y Melia, en las postrimerías del siglo pasado, por encargo de varias sociedades de orientación bibliofílica, confluyeron - por decirlo así- las dos corrientes de la especialización paleográfica y de la erudición literaria, quedando así allanado el camino para R. Menéndez Pidal. 
los demás romances, la temperatura provocada por la inquietud y tensión no cesaba de subir. En 1893 Gaston Paris, tras diez años de silenciosa reflexión concentrada sobre la controversia entre Joret y Darmesteter, hizo constar su opinión personal en un artículo que desilusionó un poco a los lectores, ya que descansaba en una premisa dudosa: un mapa de la latinidad tardía ya muy desmoronada. Para Paris las varias asibilaciones de la consonante velar representaban, en gran parte, evoluciones posteriores y mutuamente casi independientes, lo cual no dejaba de resultar chocante. Ante tal sorpresa se necesitaba cada vez más un claro dictamen de un hispanista autorizado. Este dictamen bien equilibrado es lo que proporcionó Cuervo en sus Disquisiciones del año $1895^{9}$.

De casi todos estos esfuerzos Cuervo estaba muy bien enterado al preparar su propia contribución, las Disquisiciones del año 1895; aunque no abrumaba a su futuro lector con un sinnúmero de detalles bibliográficos, señaló la importancia de los estudios de Joret y Horning sin callar sus graves deficiencias en lo que concernía al español. Declaró rotundamente que, a su parecer, lo más defectuoso en tales tentativas de rastreo no era el raciocinio, sino el propio material -en el fondo, inaprovechable- a que habían acudido, en su apresuramiento, sus predecesores. El primer paso que convenía dar era encontrar una documentación intachable. A esta altura conviene recordar que hacia principios de los años noventa, faltaban en absoluto ediciones impecablemente críticas de textos literarios escritos "por la quaderna vía", del Poema de

${ }^{9}$ Quizás sea lícito hablar de una bifurcación de pesquisas a partir de ese momento. Por un lado continúa la discusión de la $C / \mathrm{k} /$ en determinadas circunstancias, tomándose en cuenta principalmente la Antigüedad clásica y postclásica. En aquel debate, por cierto apasionante, toman parte, antes de 1930, varios comparatistas de gran talla, entre ellos P. E. Guarnerio (1897), O. Densusianu (1900), W. Meyer-Lübke (1905), M. Friedwagner (1922) y B. Migliorini (1929). En este panorama, los problemas particulares del español medieval, lejos de descollar, desempeñan un papel modesto y subordinado. Por otro lado, la enérgica intervención de Cuervo, que procuramos dilucidar aquí, dio un poderoso empuje a una serie de "tomas de posición" en un círculo más estrecho de hispanistas, quienes concentraron su atención cada vez más en el período trisecular que se extendió de 1400 a 1700 . A raíz de las Disquisiciones ventilaron el problema Ford, Saroïhandy, Tallgren y otros eruditos, cuyas respectivas aportacionés quedan por alambicar en las últimas páginas de la ponencia presente, terminando el hilo los trabajos de A. Alonso así como la reacción a ellos por parte de $\mathrm{R}$. Lapesa y $\mathrm{D}$. Catalán. A decir verdad, no se produjo ningún contacto, ni menos un diálogo fecundo, entre estos dos grupos de investigadores. 
Mio Cid, de textos alfonsinos historiográficos, jurídicos o didácticos, de los Proverbios morales de Santob y del Libro de buen Amor. Así Cuervo, en busca de autenticidad y de homogeneidad, decidió asirse de la obra prerrenacentista de Nebrija, ante todo de su Gramática castellana del año 1492 y de su Ortografía publicada exactamente un cuarto de siglo más tarde. Nebrija - como su reencarnación moderna, el propio Cuervo-, además de dominar el latín, sabía orientarse en tres lenguas clásicas: el griego ateniense, el hebreo bíblico y el árabe coránico. Además, Nebrija había recurrido a un idearium teórico, suponiendo, por ej., que a cada sonido debía corresponder una letra en un alfabeto racional; y como en el abecé de Nebrija habían figurado, sin jamás confundirse, las letras $\xi$ y $z$, Cuervo sacó de ello la acertada conclusión de que en la pronunciación de su ilustre precursor no se había producido todavía ni la mutua nivelación de la $\varsigma$ y de la $z$, ni la subsiguiente confusión del producto de su amalgama con la $s$ o ss. A pesar de la plena confianza que depositaba el erudito colombiano en el testimonio de Nebrija, se daba cuenta del riesgo que correría excluyendo otra fuente y así, a título de control y para llenar lagunas en la información que proveía el humanista de las postrimerías del siglo XV y de principios del XVI, aprovechó $E l$ arte... y, sobre todo, El vocabulista arábigo (1504), de fray Pedro de Alcalá, el moro granadino convertido al catolicismo, contemporáneo de Nebrija, así como lo poco que se había aclarado en aquel entonces sobre el judeo-español de Salónica, a base de observaciones relativamente tardías. Aun dándose cuenta de la desventaja de la distancia temporal, Cuervo se sentía animado a aprovechar el material judeo-español, dejándose guiar por los pronunciamientos de testigos antiguos sobre su valor, como Gonzalo de Illescas (1574) y Bernardo Aldrete (1614).

El núcleo del estudio de Cuervo sobre la $\varsigma$ y la $z$ (pp. 15-48) está concentrado en seis páginas muy nutridas (16-22) que corresponden al epígrafe "Ortografía y etimología". Estas páginas, que rebosan de ideas nuevas presentadas en forma calculadamente austera, se dividen en tres partes: A, B y C. Bajo A, Cuervo se ocupa de los orígenes de la $z$; bajo $\mathrm{B}$, se fija en las fuentes de la $\zeta$; estas dos secciones están organizadas de modo casi simétrico, lo que realza su utilidad. La sección $\mathrm{C}$ encierra la comparación de los resultados alcanzados y las conclusiones que se imponen a raíz de ella; ante todo, Cuervo aspira a colegir de lo que precede los caracteres generales de estas dos letras (o, como quizás preferiríamos declarar nosotros, de estos dos fonemas). 
Este esquema, aun antes de que se discutan los pormenores, muestra en seguida qué rumbo eligió el bogotano domiciliado en París: se adhirió al "plan B" de Diez, ideado en 1856, decisión que, automáticamente, le acercó a Förster y le alejó de inmediato de Joret y Horning, así como de Meyer-Lübke (1890). Le preocupaban no las peripecias de determinado sonido latino, sino las fuentes - fueran las que fueran, griegas, latinas, germánicas, árabes- de dos letras (o fonemas, para volver a modernizar su formulación) altamente características del español medieval. $\mathrm{Pa}$ ra aislar tales fuentes, resultó imprescindible etimologizar unas doscientas palabras, y es esta labor de etimologista escrupuloso, eso sí, pero también dotado de imaginación la que presta un valor particular a estas seis páginas tan jugosas.

¿Cómo está organizado ese sistema de fuentes, por ej., en lo que atañe a la $z$ ? La primera división (en $\alpha, \beta$, etc.) refleja la respectiva posición del fonema dentro de las palabras - felizmente, sin la menor atención al acento, pese a los secuaces de Verner. Así, el autor distingue la $z \alpha$ ) inicial [de palabra], reparando siempre en el reflejo, es decir, en el español nebrijense, de la misma letra, $\beta$ ) intervocálicos, $\gamma$ ) después de consonante, $\delta$ ) delante de consonante y $\varepsilon$ ) en fin de dicción. El esquema paralelo para la $\oint$ resultó, a primera vista, todavía más sencillo, contando con tres, en vez de cinco, categorías: $\boldsymbol{\alpha}$ ) inicial, $\boldsymbol{\beta}$ ) intervocálica, $\boldsymbol{\gamma}$ ) postconsonántica.

Mirado de cerca llega a ser mucho más complejo el cuadro de las subdivisiones. Así, para volver a la $z$, Cuervo, tras un breve reparo sobre la resistencia de Nebrija a la tentación de recurrir a la tal letra en voces grecolatinas como celos, celoso, celar, registra un total de ocho voces en que su precursor sí la admitió, en cuyo número figuran $\alpha \alpha$ ) cinco arabismos (zaque 'odre pequeño', zarco 'de color azul claro', zarcatona (palabra anticuada cuyo sentido desconozco), zebratana 'cerbatana' y zorzal 'pájaro parecido al tordo'; $\beta \beta$ dos voces exóticas, zebra y zangano, habiéndose anticipado el italiano al español en la adopción de la $z$; y una voz onomatopéyica: zumbar.

Huelga decir que, a medida que nos adentramos en ese matorral, aumentan las dificultades. Así, la - $z$ - intervocálica - si bien, con rarísimas excepciones, aparece tan sólo en voces de abolengo latino- no sólo procede de fuentes bastante variadas, sino que (y esto es incomparablemente más grave) depende de factores muy heterogéneos. El factor básico, en voces patrimoniales, es, desde luego, un sonido determinado o un grupo de sonidos sucesivos del latín; en general, la consonante velar sorda seguida de la se- 
miconsonante palatal. Así se explican fácilmente erizo, lizo, panizo y amenazas; además, con cierto esfuerzo, lazo, y este proceso es tan regular que, en cada ejemplo, el resultado es previsible. Pero además, como advierte Cuervo, hay unos cuantos casos excepcionales, como aquellos en que la $z$ refleja una $s$, preferiblemente seguida de yod: testigos deslizar (la única voz germánica de esta serie, de aceptarse la hipótesis bastante frágil por la que abogó Cuervo), así como cereza y cerveza, y es todavía más excepcional la $z$ como representante de la $G$ latina ante vocal anterior, como se entrevé en rezio, diáfano descendiente de rígidu. Pero el supuesto desarrollo asume un carácter ya muy distinto cuando intervienen fenómenos como la influencia asimiladora; a ella acudió Cuervo para justificar - dentro del caudal nebrijense-maciço en vez de * macizo, y creía reconocer su influjo ejercido en dirección opuesta en el caso de los numerales onze, doze, treze, catorze y quinze. (De ser así, sorprende que no haya postulado la presión de la misma fuerza también para explicar la chocante $z$ de cereza y cerveza.)

La dificultad estriba en que con frecuencia intervienen factores de categorías muy distintas, sin que Cuervo se haya empeñado en jerarquizarlas o en hacer constar explícitamente cómo encajaban en la fase decisiva del desarrollo. Así el lector se entera de que coadyuvó en la cristalización de una $z$ el haber sido la voz en cuestión un adjetivo, o un adjetivo sustantivado, ante todo si estaba provisto de ciertas terminaciones (o, como se diría hoy, sufijos de derivación), a saber, -azo e -izo - testigos bavaza, hilaza, hornaza, ...; enterizo, primerizo, ...; cañizo, granizo, caedizo, olvidadizo. Con ser todo esto muy correcto, el análisis del autor despierta nuestra curiosidad sin satisfacerla por entero, ya que no se comprende el puesto privilegiado reservado para ciertas clases de adjetivos dentro de un marco rigurosamente fonético-ortográfico sin previa discusión de la dimensión morfológica que asoma de súbito. Y la falta de tal examen preliminar del fondo teórico se hace sentir todavía más cuando se advierte la subsiguiente extensión de - azo e -izo (los respectivos productos de $\overline{\mathrm{a}} \mathrm{c}$ e u, $\mathrm{i} \mathrm{c}$ e u) a costa de morfemas de estructura más sencilla, como de hecho aconteció en los casos de mord-aza, rom-aza, ten-azas; carr-izo y tom-iza, que Cuervo, por lo demás, logró agrupar con mucho acierto.

Las seis páginas que seguimos valorando de ninguna manera constituyen mero ejercicio taxonómico; encierran una lección que, para su época, no titubeo en calificar de admirable- de escrupulosa labor etimológica. Las etimologías ora se sobrentienden, ora se indican de manera muy somera, sin discusión más allá de un simple interrogante, que a veces acompaña un aserto 
dudoso o un dilema; así, el autor se pregunta si hechizo proviene de $\mathrm{f}$ a $\mathrm{c} t \overline{\mathrm{i}} \mathrm{c}$ i u s o de $\mathrm{f}$ i c t $\overline{\mathrm{i}} \mathrm{c}$ i u s. Los asteriscos para bases hipotéticas se introducen rara vez, con todo esmero, como con motivo de mellizo ( ${ }^{*} \mathrm{~g} \mathrm{e} \mathrm{m} \mathrm{e} \mathrm{lli} \mathrm{i}$ i u s) y de ceniza $\left({ }^{*} \mathrm{c}\right.$ i n i c i a). Cuando la base inmediata de la voz castellana se aleja de la forma clásica, Cuervo se contenta con una alusión, así a propósito de ceuadazo, que, cuando más, se parece tipológicamente - a h o rd e $\bar{a}$ c e u s; y de lampazo, que recuerda, eso sí, l a p p à c e u s, pero todavía carece de la nasal intercalada; y de advenedizo, que representa un prototipo ( $\mathrm{a} d \mathrm{v}$ e $\mathrm{n} \mathrm{t} \overline{\mathrm{i}} \mathrm{c} \mathrm{i} \mathrm{u}$ s) muy remozado en su esquema morfológico. Donde el material recopilado le suministra dos variantes, como en el caso de fuzia y fiuzia 'confianza', Cuervo las recoge y consigna su dependencia de la misma base, por ej. $f \bar{\imath} d \bar{u} c$ i a, sin enzarzarse en detalles. Frente a "unas cuantas voces de origen o evolución fonética oscura', no vacila en admitir su ignorancia con toda ingenuidad, negándose a dictaminar sobre aziago 'infausto', enaziado 'tornadizo' y la pareja acezar 'jadear' y bocezar 'mover los labios el caballo hacia uno y otro lado, bostezar', lo que es prueba de cautela, y aun sobre gozo y go$z a r$, lo que ya atestigua un escrúpulo exagerado, no siendo nada difícil la construcción de un puente entre gozo y g a u d i u m. Registra las voces arábigas por separado e identifica con toda brevedad la consonante semítica en cuestión, sin proveer etimologías, como si resistiese a la tentación de abrumar al lector no orientalista con toda clase de bases exóticas. Dado el conjunto de tan sensatas normas de conducta, no causa sorpresa que el número de errores sea mínimo, si bien en alguno que otro caso un investigador de nuestra época desde luego se inclinaría a ofrecer una formulación algo distinta; me refiero a bozina, que, a mi entender, ha de ser producto de $\mathrm{b} \overline{\mathrm{u}} \mathrm{c}$ i $\mathrm{n}$ a alterado por asociación con boca y voz; a deslizar, de cuyo germanismo estamos mucho menos convencidos en la actualidad de lo que estaba la generación de Cuervo; y a alguno que otro más caso de étimo controvertido.

Desde luego, no es lícito examinar aquí con igual lujo de detalles el resto del análisis de Cuervo ${ }^{10}$.

${ }^{10}$ Sobre la fragmentación de f I d u c i a 'confianza', que llevó a la formación de una tríada en español antiguo (fiuzia, fiuza, fuzia; nótense, a principios del siglo Xvı, ahuizar y huzia, que sobreviven en una típica reliquia léxica, desahuciado), véase mi estudio de 1977; examino las fortunas de g a u d e r e y g a u d i u m en un artículo breve del año 1979. Me ocupo del zigzagueo de las opiniones sobre el rumbo que siguieron las parejas almuerzo/almorzar y port. almoço/almoçar en dos artículos paralelos, que están en prensa. No repito la lista de estudios anteriores a 1966 que figura (en nota) en mi trabajo arriba 
En resumidas cuentas, mostró una técnica, una finura y una intuición realmente impresionantes, envidiables en el nivel de la diagnosis etimológica, acertando casi siempre con sus juicios dentro de los límites de la mejor ciencia de su época, que él se negaba a traspasar. En el nivel de conclusiones de carácter más general, empero, alternaban en sus veredictos hipótesis que hoy siguen pareciendo felicísimas con otras que nos sentimos autorizados a rechazar por lo menos en parte. Por ejemplo, a diferencia de lo que ocurrió con su Diccionario, Cuervo mostró escaso interés por el ingrediente cronológico de los problemas que se le plantearon en las Disquisiciones. Así, insistió en que la - $z$ - de clerezía, en clara contradicción con la -c-de abogacía y legacía, se explicaba por la presencia de una $\mathrm{C}$ en c l e ri c u s, mientras a d v o c a t u s y $1 \overline{\mathrm{e}} \mathrm{g} \overline{\mathrm{a}} \mathrm{t} \mathrm{u} \mathrm{s}$, al revés, mostraban una T. Observación innegablemente justa; pero agréguese el hecho de que clerezía pertenece a una capa del léxico mucho más antigua que voces medio artificiales, como abogacía y legacía.

Guervo reconoció certeramente, sin saber explicarlo bien, el chocante desarrollo de dos sufijos, a saber, -azón y -eza, en vez de ${ }^{*}$-açón y ${ }^{*}$-eça, que los antecedentes y los paralelos nos llevan a postular como los productos "ideales"; pero, al parecer, no se daba cuenta de que la familia de sufijos verbales -azar, -izar, -uzar (como en adelgazar, bautizar y desmenuzar), a que se refirió en otro contexto, adolecía de la misma dificultad. Le causó honda inquietud descubrir que razón y sazón se comportaban como los abstractos verbales en -azón (por ej., castrazón), mientras coraçón parecía oponerse a tal corriente. Pero, volviendo a analizar hoy ese material en el nivel temporal del latín, se echa de ver en seguida que los respectivos étimos de estas voces, $\mathrm{r}$ a $\mathrm{t}$ i $\overline{\mathrm{o}}$ y s a $\mathrm{t} \mathrm{i} \overline{\mathrm{o}}$ (en estrecho enlace con $\mathrm{s} t$ a $\mathrm{t} \mathrm{i} \overline{\mathrm{o}}$ ), eran de hecho, en un principio, abstractos verbales, de modo que no debería causar sorpresa descubrir su perfecta congruencia con la evolución de c a s t r a t i ó, mientras nuestro análisis de coraçón dependerá del punto de partida que elijamos (y Cuervo no se atrevió a pronunciarse sobre esa materia delicada) ${ }^{11}$. Otro terreno resbaladizo es el del sufijo -eza.

mencionado sobre algunas aplicaciones erróneas de la Ley de Verner; se reanudan varias discusiones, a veces desde puntos de vista diversos, en un artículo reciente (1981), de mayor envergadura.

11 Sobre el encauzamiento especial de los sufijos -azón, -izón, etc. formulé una conjetura en 1971; y para la formación de coracón como un compuesto de esquema luego borrado y desdibujado propuse una hipótesis ya con anterioridad, en 1958. No me consta que hayan provocado mucha discusión estos dos estudios. 
El autor, reconociendo la frecuencia, aun en lo antiguo, del sufijo mellizo -ez (como en vej-ez, derivado de viejo), supuso que -eza podía haberse arrimado a $-e z$ (a decir verdad, no se ve a las claras si aludía a la ortografía, a la pronunciación o a ambas). De todos modos, de haber tenido presente en aquel momento la mayor complejidad del antiguo gallego-portugués, quizás se ceñiría a un interrogante y evitaría una conjetura tan frágil. Porque en el Oeste de la Península las formas que correspondían a vej-ez eran velh-ece y velh-ice, ambas con $c$, sin que esto impidiese que figurara -eza en el inventario local de los sufijos. Prefiero no desarrollar aquí mi propia tentativa de explicación, que ya ofrecí hace unos diez años. Por lo demás, el propio Cuervo, al terminar su examen, se apresuró a admitir, con su probidad intelectual de siempre, que el esquema propuesto no eliminaba un residuo nada pequeño de contradicciones, que - agrego por cuenta mía- olían a excepciones, lo cual no armonizaba bien, por supuesto, con las exigencias (vigentes en aquel entonces) de los inexorables neogramáticos.

Lo que sigue de inmediato a estas seis páginas saturadas de hallazgos, repletas de ideas nunca triviales, de datos rarísima vez inexactos no deja de ser, hasta cierto punto, anticlimáxico. Seguramente, consciente de que el testimonio de Nebrija, por notable que fuese, adolecía de su fecha muy tardía frente al conjunto de la Edad Media española y, además, de su posible matiz dialectal (andaluz, por supuesto) así como de otras idiosincrasias, Cuervo decidió acarrear, a título de control, otros materiales, ya menos fidedignos, sobre la ortografía coetánea y anterior a Nebrija; esta colección de datos auxiliares se extiende desde algunos instrumentos notariles de los siglos décimo, undécimo y duodécimo ${ }^{12}$ a través de los fueros de Madrid y Avilés y los Reyes Magos en la edición de Baist, el epitafio de la Catedral de Toledo (que lleva la fecha de 1278) y uno de los mejores manuscritos del Fuero Juzgo (que Cuervo pudo examinar en París) hasta el Cancionero de Stúñiga, el de Baena y varios textos del siglo XV publicados por $\mathrm{H}$. Knust. Pero ni los antiguos autores de tales textos tenían el oído refinado de Nebrija; ni los copistas brillaban por un exceso de escrupulosidad; ni tampoco los paleógrafos, archiveros, filólogos e impresores del siglo XIX encargados de las respectivas ediciones

${ }^{12}$ Como ávido lector de esos materiales - sólo a primera vista algo aburridos-, Cuervo allanó el camino a R. Menéndez Pidal, quien, por supuesto, estando radicado en España y no en el extranjero, aprovechó los propios manuscritos (originales o copias) en el t. 1 de su libro magistral, Documentos lingüísticos de España. 
comprendían a fondo el problema "técnico" que Cuervo se había propuesto solucionar; de manera que estas páginas, con rebosar de mucha "materia prima"' sobre la $z$ y la $\varsigma$, desilusionan en el fondo.

Sigue a ese subcapítulo otro, el más largo de todos, que abarca unas veinte páginas (29-48) y se titula "Pronunciación"; se puede caracterizar como una especie de preludio a una obra de sesgo parecido, si bien de proporciones y finalidad muy distintas: me refiero al trabajo de principios de los años cincuenta de Amado Alonso, publicado póstumamente en dos tomos, De la pronunciación medieval a la moderna en español ${ }^{13}$. Hasta cierto punto se trataba aquí de captar el detalle fonético, a base de testimonios de antiguos ortoepistas y gramáticos, de dos procesos tan lentos y paulatinos que resultaban difíciles de observar: la pérdida de la africación en todo el territorio peninsular (y aun de ultramar); y la transformación de las sibilantes hechas acéfalas ora en una $/ \theta /$, ora en una $/ \mathrm{s} /$ - siendo esa $/ \mathrm{s} /$, en el nivel fonético, muy distinta de la /s/ acústicamente palatal de las Castillas. Llama la atención el hecho de que Cuervo se desentendió por completo de un proceso que hoy nos parece afín a las vicisitudes de la $z$ y la $\zeta$, a saber, la formación de la $c h / c /$, muchas veces formidable rival de la $̧$ en lo antiguo (compárese la alternancia de aguacha y agua$z a$, para ceñirme a una sola pareja de "dobletes"). Además, la $c h$, la $\varsigma$ y la $z$ compartían la africación en el nivel cronológico de la Edad Media; y si la ch logró conservar este rasgo en español ${ }^{14}$, lo perdió en cambio en la gran mayoría de los dialectos portugue-

${ }^{13}$ Para un resumen bastante detallado del extenso capítulo en cuestión puede consultarse mi reseña del primer tomo. Entre las reacciones críticas a la obra póstuma de A. Alonso es justo subrayar la importancia de aquellas que contribuyeron D. Catalán y R. Lapesa a raíz de su publicación. En rigor, los estudios de Alonso sobre el seseo y ceceo se jalonan a lo largo de más de dos decenios; quien desee releerlos en su conjunto puede aprovechar la Bibliografía que precede a la miscelánea dedicada a la memoria de Amado Alonso en la Nueva Revista. Llama la atención el escaso influjo que ejerció el libro, por lo demás serio y nutrido, de $\mathrm{H}$. Gavel, que por un motivo u otro no hizo mella, indiferencia que quizás explique la violenta decisión del autor de dedicarse de allí en adelante a la investigación del vascuence, en merma de la filología hispánica.

${ }^{14}$ Aunque varios dialectos, precisamente entre los de ultramar (por ej., los de Chile), muestran el relajamiento de/č/ en /s/, según quedó demostrado más de una vez precisamente en el Congreso de San Juan (octubre de 1982) que sirvió de marco para la presente ponencia. Véase, entre otros, el utilísimo trabajo de Carmen Silva Corvalán. 
ses, igual que, desde luego, en todas las variantes del portugués literario. Además de esos problemas, muy reñidos, de la fonética, Cuervo se veía obligado a contestar a una pregunta ya menos espinosa, que hoy llamaríamos de orden fonológico: ¿Cuándo se produjo la neutralización del contraste (o de la oposición) entre la $z$ sonora y la $\varsigma$ sorda? A esta pregunta consiguió dar una respuesta, en efecto, muy neta: en la primera mitad del siglo XVII (p. 29), es decir - agrego por cuenta mía - verosímilmente cuando ya estaban desafricados los dos fonemas en cuestión. Un rasgo pintoresco de la discusión de Cuervo fue el grado de atención que prestó a la extraña hipótesis de Nebrija - formulada en la Gramática, en la Ortografia y aun en el tratado De literis hebraicis - de que en un principio la $\varsigma$ y la $z$ eran ajenas al caudal fónico de la latinidad hispánica, debiéndose su introducción al contacto con moros y judíos. Hoy se sabe de fijo que estos últimos, al revés, tendían a asimilar su propia pronunciación del hebreo -lengua de plegaria, no de conversación en aquel entonces- a las muy variadas preferencias locales de su ambiente, en España igual que en otros países de su destierro y dispersión.

Con ser éstas veinte quizás las páginas que hoy más estimulen e inquieten al estudioso de la dialectología andaluza e hispanoamericana, de ningún modo fue así a fines del siglo pasado. Dada la elevada curiosidad por la etimología y la gramática histórico-comparada, fue el registro esquemático de las fuentes el que no tardó en provocar reacciones críticas, tanto más como que el autor fue el primero en admitir, con la honradez intelectual que siempre le caracterizaba, que varios problemas - en lo que atañía a lagunas y a contradicciones chocantes - quedaban por resolver, literalmente pidiendo ayuda a individuos de preparación adecuada y buena voluntad. Quienes más se apresuraron a socorrerle con su crítica no fueron ni españoles ni menos hispanoamericanos, sino personas de alta calificación técnica que pertenecían a varias culturas extranjeras: un muy joven investigador norteamericano, Jeremiah D. M. Ford, que por aquellos años se preparaba en Harvard para el doctorado en filología románica; un brillante explorador del terreno pirenaico, de formación universitaria francesa pero de abolengo vasco, Jules Saroïhandy; y un finlandés que se trasladó a Madrid para trabajar con apasionamiento en el ambiente de un Ramón Menéndez Pidal todavía joven: Oiva Johannes Tallgren (quien en lo sucesivo cambió de apellido, adoptando el de Tuulio, de apariencia menos sueca y más auténticamente fénica). A estos tres hispanistas 
jóvenes se les agregaron otros, quizás menos empeñados ${ }^{15}$, para no decir nada de autores de gramáticas históricas, como Menéndez Pidal, Zauner y Hanssen (cada uno de ellos en más de una ocasión). De todos modos, conviene caracterizar con toda brevedad el aporte de cada aliado (o contrincante) de aquella primera generación de admiradores entusiastas y, a la vez, críticos de Cuervo, ninguno de ellos - repito - su compatriota. (A la inversa, los estudios monográficos que salieron después de 1910 -es decir, los de F. Krüger y M. L. Wagner, los cuales aparecieron en vísperas de la Primera Guerra Mundial, y el de Aurelio M. Espinosahijo, que pertenece a los años treinta, aun con presuponer la familiaridad de sus respectivos autores con el opúsculo de Cuervo, ya no merecen el marbete de meras reverberaciones.) Además, el escrupuloso examen del uso prealfonsino de la $z$ y la $\varsigma$ que llevó a cabo, por primera vez, Menéndez Pidal en sus Orígenes (1926) marcó un cambio radical de perspectiva.

Cuando salió en su redacción original la primera parte de las Disquisiciones de Cuervo, Ford tenía unos veintidós años: era mero mozalbete y, desde luego, no podía respaldarse en ninguna pesquisa anterior organizada por cuenta propia. Entre sus profesores descollaban - como era de esperar, tratándose de un centro universitario como Harvard- varios eruditos norteamericanos de primera fila, entre ellos el romanista Charles Grandgent, el anglicista George Kittredge y el medievalista E. S. Sheldon. Este último, a juzgar por su actitud muy optimista, fue quien animó a su alumno predilecto a examinar con esmero casi exagerado y en clave crítica ciertas partes de la sensacional monografía de Cuervo -en gran parte la historia de la $z$ y la $\varsigma$, pero también, aunque con menor detenimiento, las peripecias de la $s$ simple y doble, de la $x$ pronunciada / $/$ /, así como de la pareja $j / g^{e, i}$. Me imagino que Ford, en aquel momento, estaba en busca de un tema apasionante para su tesis de doctorado, un asunto que le colocase de inmediato en la primera fila de investigadores; era un joven ambicioso, tenaz y trabajador. Todo esto podemos inferir de la estupenda rapidez con que llevó a cabo el proyecto de indagación emprendido. En efecto, a lo sumo a los dos años de labor muy intensa consiguió presentar su famosa tesis, The Old Spanis'h Sibi-

${ }^{15}$ Así, la monografía de Juraszek, dedicada a otro idioma, tiene tan sólo dos páginas apretadas sobre las peripecias de la $\varsigma$ y $z$ del español antiguo. Hasta cierto punto, pertenecen a esta etapa de la discusión varios pasajes del meritorio estudio de J. Subak (discípulo directo de Meyer-Lübke en Viena), sobre el judeo-español de Bosnia y de Constantinopla. 
lants que, pasados otros tres años (es decir, en 1900), salió como monografía de 192 páginas de texto impreso, ocupando casi por entero el t. VII del prestigioso anuario, [Harvard] Studies and Notes in Philology and Literature (confundiéndose por entonces todavía los terrenos de la filología propiamente dicha y de la lingüística histórica). El trabajo dio lugar a varias reseñas en las mejores revistas europeas ${ }^{16}$, entre ellas una firmada por Meyer-Lübke, que así acometió el problema por tercera vez; otra reseña emanó de Horning, el verdadero culpable por la notoriedad del asunto tan debatido.

Visto en esta perspectiva, el trabajo de Ford encerraba una especie de desafío, por parte de un principiante un tanto arrogante, lanzado a un erudito de gran talla y de impresionante madurez de juicio. Para alcanzar su meta, Ford se tomó la molestia de hojear, tomo tras tomo, todas las revistas de filología románica asequibles, ante todo las muy prestigiosas de lengua alemana, para formarse una idea de las controversias etimológicas que concernían a las palabras en cuestión. Además consultó muchos libros, antiguos y modernos; la bibliografía que compiló excede de cinco páginas. Así, donde Cuervo se contentaba con breves alusiones dignas de un perito sofisticado ${ }^{17} \mathrm{o}$, por su elocuente silencio, daba por aceptadas numerosas soluciones, Ford alardeó, con cierta pesadez típica de un principiante, la inagotable abundancia de su fichero. Aburrió a sus lectores con diez páginas de cultismos, cuyo testimonio es inútil. En algunos casos ofreció, a título de alternativas, sus propias conjeturas, a decir verdad, no muy interesantes, ni siquiera atrevidas. Como por aquellos años ya comenzaban a pulular las ediciones críticas de textos medievales, aprovechó varias para entresacar ( $\mathrm{y}$ así documentar) gran número de voces con $z$ y $\mathrm{c}$. La investigación culminó en una tabla o

${ }^{16}$ La Zeitschrift für romanische Philologie - quizás la más prestigiosa de todas en aquella época- inclusive publicó dos críticas, una de Horning, a la que aludo más adelante, y la otra de Herzog.

17 Téngase en cuenta que ya la primera de las célebres Notas que redactó Cuervo a título de un comentario a la Gramática de la lengua castellana de Andrés Bello giraba, en parte, en torno al uso de la $c$ y de la $z$ en los autores antiguos; véanse las pp. 23-34 de la importante edición crítica que debemos a Ignacio Ahumada Lara (1981). Si comprendo bien a este investigador, la redacción de dicha Nota ya andaba muy adelantada en las ediciones de 1891 y 1892 (la primera edición de la obra se remonta a 1874); circunstancias que explican satisfactoriamente la madurez de juicio que lució Cuervo en sus Disquisiciones del año 1895, que a su vez le ayudaron a ofrecer el texto definitivo de la Nota en la edición de 1898 . 
lista (pp. 87-88), que registraba, para la $z$, cuatro fuentes fidedignas, cinco problemáticas o chocantes $\mathrm{y}$, otra vez, cinco seguramente falsas; las cifras correspondientes para la $\xi$ eran nueve, cuatro y, de nuevo, cuatro. Desgraciadamente, cuanto Ford rechazaba como dudoso o ilógico ("apparent sources, from which its evolution could hardly be expected"), repetidas veces terminó por ser reivindicado con mucho éxito, ya no teniendo ni sombra de extrañeza, como la $z$ de enzía, senzillo y esparzir/-er.

Trataré de describir y caracterizar con mayor brevedad los trabajos de Saroíhandy y Tallgren-Tuulio. Desconozco en absoluto la prehistoria del artículo de aquel que, en 1902, salió en t. IV del Bulletin Hispanique de Burdeos, revista dirigida por aquellos años por su fundador, el futuro decano Georges Cirot. Así y todo, sospecho que en un principio se trataba de una reseña que había encomendado Cirot al sabio profesor del liceo de Versalles -ora del artículo monográfico de Cuervo, ora del libro recién publicado de Ford, ora de ambos. De haber pasado así las cosas, conviene suponer que las proporciones de la reseña terminaron por exceder de la norma estipulada, y que el benévolo director y el concienzudo crítico se pusieron de acuerdo sobre la necesidad de transformar el resumen, las observaciones y los reparos en un artículo independiente de 17 páginas muy concentradas, titulado "Remarques sur la phonétique du $\xi$ et du $z$ en ancien espagnol". Nótese el ámbito programático mucho más estrecho que en los casos anteriores y paralelos del artículo de Cuervo y de la tesis de Ford. Fue, en efecto, Saroïhandy el primero en reconocer el intrínseco desnivel entre la complejidad de este problema particular y la mucho menor de los demás problemas que habían obsesionado a sus precursores.

Examinado en proyección retrospectiva, el trabajo de Saroíhandy resulta útil y honesto, pero carece de una nota dramática, por la sencilla razón de que, en el fondo, Cuervo y Ford casi no diferían en sus juicios; por lo tanto, no se trataba de tomar decisión o de desempeñar el papel de un árbitro. Dada tal situación, Saroïhandy colmó de elogios a sus dos predecesores; resumió ambas investigaciones; llenó varias lagunas bibliográficas; se pronunció sobre alguno que otro punto oscuro; y proveyó la parte más técnica de su artículo de un aparato etimológico mucho más sistemático, y por lo tanto, más pesado que aquel a que había acudido Cuervo.

En cuanto a Tallgren, su tarea principal, allá por 1905, era preparar una edición crítica, a base de un solo manuscrito, del primer diccionario de rima español -inédito en aquel entonces- 
que se escribió jamás, se supone que alrededor del año 1430 . El nombre del antiguo compilador era Pero Guillén de Segovia, y la obra se titulaba La gaya [ciencia] o Consonantes. Últimamente se publicó en Madrid en 1962, más de dos decenios después de la muerte del benemérito investigador finlandés; en efecto, salió en circunstancias bastante dramáticas que no hacen al caso. Pero ya de joven principiante, allá por 1905, Tallgren reparó en el caudal de preciosos datos que su material ofrecía para la aclaración del problema filológico más reñido y, a la vez, más urgente de aquella época en el ambiente de hispanistas -el de las sibilantes medievales. Así se dejó desviar brevemente de su compromiso principal y separó de una monografía de gran envergadura sobre una figura del siglo XV su análisis de la $z$ y la $\varsigma$ iniciales de sílaba a base de las preferencias del propio autor o del copista - los dos, por cierto, anteriores a Nebrija y así, hasta cierto punto, más fidedignos como testigos del uso de la Edad Media. Nótese la estrechez cada vez mayor del problema que se planteaba ante los peritos: para desbrozar el terreno, Tallgren, superando en este respecto a sus tres predecesores, ¡se ciñó a la $z$ y la $\xi$ iniciales de sílaba! Una primera versión de su estudio, redactado en español, salió en un excelente anuario local dedicado expresamente a la filología, con varias enmiendas y no pocas adiciones relegadas a un Suplemento que figuraba en el mismo tomo; a los dos años, se publicó, otra vez en Helsingfors (como todavía se llamaba Helsinki entonces), un texto más nulido, ya como último capítulo de la tesis entera.

Lo que nadie sospechaba por aquellos años es que el propio Cuervo, quien - con su discreción de siempre - se abstuvo de tomar parte en la controversia, a pesar de aquel largo silencio seguía revisando la primera parte de sus Disquisiciones que habían dado tan fuerte y noble empuje a la ciencia europea y aun norteamericana. Cuando murió en 1911, dos años antes de Saussure, dejó a la posteridad un manuscrito de la nueva versión, muy ampliada en lo que atañía a la biografía y documentación de cada una de las voces-clave. La ironía arraiga en que dicha redacción, con ser infinitamente superior a la original de 1895, salió a luz solo en 1944, figurando en las Obras inéditas del maestro colombiano $^{18}$. Entonces soplaba ya un viento muy distinto, y las nuevas vanguardias de lingüistas se negaron a prestar a esa ver-

18 Una colación sistemática de las dos redacciones - página por página y aún línea por línea- rendiría por cierto unos resultados muy notables; que- 
sión tan valiosa y personal ni una modestísima parte de la atención que sí había prestado una generación menos mimada a un texto que, a bien mirar, en el fondo era mero esbozo de la obra definitiva ${ }^{19}$.

YAKOV MALKIEL

University of California, Berkeley

da por hacer todo. Hoy por hoy podemos sentar lo siguiente. El texto revisado y ampliado de las Disquisiciones (I) ocupa las pp. 351-492, sin contar las muy elaboradas aclaraciones bibliográficas (pp. xix-xliv) que estaban a cargo de $\mathbf{P}$. U. González de la Calle y que facilitan mucho la lectura y la consulta. Parece que Cuervo se desentendió de cualquier tentativa de revisar la Segunda Parte (de 1898), quizás por parecerle adecuada la versión original o por haber figurado en el examen de los cultismos relativamente pocas incógnitas (faltando, por ej., el ingrediente etimológico). El texto revisado y puesto al día figura también en las Obras (t. 2, pp. 344-476), acompañado de un comentario útil por parte de Rafael Torres Quintero. Intercalado a medio camino en ese tomo hay un "Índice de vocablos y expresiones" (pp. 804-832), el cual abarca, a más de las dos versiones del tratado que está sobre el tapete, otros varios tratados del autor, de la misma índole.

Salta a la vista - además del tamaño doble que alcanzaron las Disquisiciones (I) a raíz de la revisión (así, el capítulo sobre $\zeta$ y $z$ se extiende ahora desde la p. 372 hasta la p. 464, resultando así el más enérgicamente ampliado)el aparato de anotaciones realmente excepcional. Así, muy lejos de mencionar de pasada una voz anticuada como arcabuz (pp. 410 ss.). Cuervo no sólo documenta con citas concretas los derivados primarios y secundarios (arcabuz-ero, -ería, -azo) con las respectivas variantes ortográficas, sino que abona las voces congéneres del francés y del italiano (faltando sólo la documentación del portugués) y ofrece al lector un caudal de alusiones al uso de aquella voz técnica en numerosos autores españoles de los siglos XV a XVII, incluyendo no sólo un Cervantes sino también un Luis de Ávila y Zúñiga (y otros varios historiógrafos) y un Gonzalo de Ayora.

19 No salió en los años cuarenta, que yo sepa, una sola reseña del libro digna de la ocasión (verdad es que, en parte, retardó su difusión la Segunda Guerra Mundial). 


\section{APÉNDICE BIBLIOGRÁFICO}

Alcalá, Pedro de. Arte para ligeramente saber la lengua aráviga; Vocabulario arávigo, Granada, 1504-5; facsímil, Hispanic Society of America, New York, 1928.

Aldrete, Bernardo. Varias antigüedades de España, África y otras provincias, Juan Habrey, Amberes, 1614.

Alemany Bolufer, José. Estudio elemental de gramática histórica de la lengua castellana, Tipografía de la $R A B M$, Madrid, 1902; $2^{\mathrm{a}}$ ed., 1903; $6^{\mathrm{a}}$ ed., 1928.

Alonso, Amado. De la pronunciación medieval a la moderna en español, ultimado y dispuesto para la imprenta por Rafael Lapesa, t. 1, Gredos, Madrid, 1955; $2^{\mathrm{a}}$ ed. (rev.), 1967.

Baist, GotTfried. Alter und Textüberlieferung der Schriften Don Juan Manuels, disertación Erlangen, Imprenta de E. Karras, Halle, 1880.

- (ed.) Don Juan Manuel. El libro de la caza, zum erstenmale herausgegeben, M. Niemeyer, Halle, 1880.

- . "Die spanische Sprache", en G. GRÖBER, Grundriss der romanischen Philologie, t. 1, pp. 689-714, K. J. Trübner, Strassburg, 1888; $2^{a}$ ed. (rev.), pp. 878-915, Strassburg, 1904-6.

Catalán Menéndez-Pidal, Diego. "The End of the Phoneme $z$ in Spanish", Word, 13 (1957), 283-322.

Chabaneau, Camille. Reseña de Joret [1874], RLR, 7 (1875), 403-408.

Cornu, Jules. "Die portugiesische Sprache", en G. GröBer, Grundr riss der romanischen Philologie, t. 1, pp. 715-803, K. J. Trübner, Strassburg, 1888; $2^{\mathrm{a}}$ ed. (rev.), pp. 916-1037, Strassburg, 1904-06.

Corominas, Joan (o JuAn). Diccionario crítico etimológico de la lengua castellana, 4 ts., Gredos, Madrid; Francke, Bern [1954-57].

Cuervo, Rufino JosÉ. 'Disquisiciones sobre antigua ortografía y pronunciación castellanas, I', RHi, 2 (1895), 1-69.

- . "Disquisiciones sobre antigua ortografía y pronunciación castellanas, II', $R H i, 5$ (1898), 272-307.

- Disquisiciones filológicas, comp., introd., notas y dirección de imprenta de Nicolás Bayona Posada, , Editorial Centro, Bogotá, 1939,2 ts.

- Obras inéditas, ed. Félix Restrepo y Pedro Urbano González de la Calle, Publicaciones del Instituto Caro y Cuervo, Editorial Librería Voluntad, Bogotá, 1944.

- . Disquisiciones sobre filología castellana, bajo la dirección de Luis Alfonso, El Ateneo, Buenos Aires, 1948.

_. Disquisiciones sobre filología castellana, ed., pról. y notas de Rafael Torres Quintero, Instituto Caro y Cuervo, Bogotá, 1950. 1950.

- Obras, ed. Rafael Torres Quintero, Instituto Caro y Cuervo, Bogotá, 1954, t. 2. 
Epistolario de... y Raymond Foulché-Delbose, ed. Charles Leselbaum, Instituto Caro y Cuervo, Bogotá, 1977.

[Cueto, Leopoldo de, marqués de Valmar, ed.] Alfonso el Sabio, Cantigas, Real Academia Española, Madrid, 1880, 2 ts.

Darmesteter, Arsène. Reseña de Joret [1874], Ro, 3 (1874), 379-398.

Densusianu, Ovid. "Sur l'altération du $c$ latin devant $e, i$ dans les langues romanes", Ro, 29 (1900), 321-333.

Diez, Friedrich. Grammatik der romanischen Sprachen, 3 ts., Eduard Weber, Bonn, 1836-44; $2^{\mathrm{a}}$ ed. (rev.), 1856-60; $3^{\mathrm{a}}$ ed. (rev.), 1870-72.

Elliott, A. Marshall. Reseña de Horning [1883], AJ, 5 (1884), 104-107.

Espinosa, Aurelio M. (hijo). Arcaísmos dialectales; la conservación de la "s" $y$ "z» sonoras en Cáceres y Salamanca, Anejo 29 a la RFE-Centro de Estudios Históricos, Madrid, 1935.

FiTA Y Colomé, Fidel (ed.). Legis Romanae Wisigothorum fragmenta ex codice palimpsesto sanctae Legionensis ecclesiae..., apud Ricardum Fe, Matriti, 1896.

Förster, Paul. Spanische Sprachlehre, Weidmannsche Buchhandlung, Berlin, 1880.

Ford, Jeremiah D. M. The Old Spanish Sibilants, en [Harvard] Studies and Notes in Philology and Literature, 7 (1900), 1-192.

- Old Spanish Readings, Selected on the Basis of Critically Edited Texts. $2^{\mathrm{a}}$ ed., International Modern Language Series, Ginn, Boston, 1911; reimpresa en 1939.

FriedwaGner, M. 'Zur Aussprache des lateinischen C vor hellen Vokalen", en Hauptfragen der Romanistik; Festschrift für Philipp August Becker, Heidelberg, 1922, pp. 37-49.

Gavel, H[ENRI]. Essai sur l'évolution de la prononciation du castillan depuis le xiv siècle, d'après les théories des grammairiens et quelques autres sources, É. Champion, Paris, 1920.

Gayangos, Pascual de (ed.). Escritores en prosa anteriores al siglo xv, BAE, t. 51, M. Rivadeneyra, Madrid, 1851.

GorRa, EgIDIO. Lingua e letteratura spagnuola delle origini, Ulrico Hoepli, Milano, 1898.

Guarnerio, Pier E. "L'intacco latino della gutturale $c e c i$ ", AGIt, suppl., 4 (1897), 21-51.

Hanssen, Federico. Spanische Grammatik auf historischer Grundlage, Niemeyer, Halle, 1910.

- Gramática histórica de la lengua castellana, Niemeyer, Halle, 1913.

Herzog, Eugen. Reseña de Ford [1900], ZRPh, 26 (1902), 362-364.

Horning, Adolf. Zur Geschichte des lateinischen C. vor E und I im Romanischen, Niemeyer, Halle, 1883.

—. Reseña de Ford [1900], ZRPh, 26 (1902), 360-362.

Illescas, Gonzalo DE. Historia pontifical y católica..., Salamanca, 1569; Salamanca, 1577; Burgos, 1578, etc. 
Janer, Florincio (ed.). Poema de Alfonso Onceno, rey de Castilla y de León, Manuscrito del siglo XIV, publicado por primera vez... con noticias y observaciones de..., Impreso por Rivadeneyra, Madrid, 1863.

Joret, Charles. Du C [latin] dans les langues romanes, A. Franck, Paris, 1874 ( = Bibliothèque de l'École des Hautes Études, 16).

Jukoszek, L. J. “Ein Beitrag zur Geschichte der jotazierten Konsonanten im Französischen”, ZRPh, 27 (1903), 550-578, 675-707.

Keller, Adolf. Altspanisches Lesebuch mit Grammatik und Glossar, F. A. Brockhaus, Leipzig, 1890.

KrüGER, FRITZ. Studien zur Lautgeschichte westspanischer Mundarten, auf Grund von Untersuchungen an Ort und Stelle, Mitteilungen und Abhandlungen aus dem Gebiet der romanischen Philologie, 2, L. Gräfe \& Sittem, Hamburg, 1914.

LAPESA, RAFAEL. "Sobre el ceceo y el seseo en Hispanoamérica", RevIb, 21 (1956), 409-416.

- . "Sobre el ceceo y el seseo andaluces", en Miscelánea homenaje a André Martinet: Estructuralismo e historia, t. 1, Gredos, TenerifeMadrid, 1957, pp. 67-94.

Lauchert, Friedrich (ed.). "La estoria del Rey Anemur e de Josaphat e de Barlaam", $R F, 7$ (1895), 331-402.

(ed.). La estoria de los quatro dotores de la santa eglesia. Die Geschichte der vier grossen lateinischen Kirchenlehrer, in einer alten spanischen Übersetzung... Romanische Bibliothek, 14, Niemeyer, Halle, 1897.

Malkiel, Yakov. Reseña de A. Alonso [1955], RPh, 9 (1955), 237-252.

- "Español antiguo cuer y coraçón", BHi, 60 (1958), 180-207, 327-363.

- ' 'Quelques fausses applications de la 'Loi de Verner' aux faits romans", CFS, 1966, núm. 23 ["Hommage à André Burger"], 75-87.

- "Derivational Transparency as an Occasional Co-Determinant of Sound Change. A New Causal Ingredient in the Distribution of $-c$ - and $-z-\ldots$ in Ancient Hispano-Romance", $R P h, 25$ (1971), 1-52.

- "La fragmentación de $\mathrm{f} \overline{\mathrm{I}} \mathrm{d} \overline{\mathrm{u}} \mathrm{c}$ i a en hispanorrománico", NRFH, 26 (1977), 1-55.

"La vacilación fonética como causa de una pérdida léxica: En torno al desarrollo de $\mathrm{g}$ a $\mathrm{u} \mathrm{d}$ e $\mathrm{r}$ e y $\mathrm{g}$ a $\mathrm{u} \mathrm{d} \mathrm{i}$ u $\mathrm{m}$ en hispanorrománico", en Homenaje a Fernando Antonio Martínez... (Instituto Caro y Cuervo, Bogotá, 1979), pp. 34-54.

"A Hidden Morphological Factor Behind Instances of Erratic Distribution of $\zeta$ and $z$ in Old Spanish?", $R P h, 35$ (1981), 105-129.

" "Los dos núcleos de almuerzolalmorzar: el latino y el prelatino", en Festschrlft für Johannes Hubschmid (Francke, Bern - München, 1982), pp. 961-984.

- «Some Second and Third Thoughts on Luso-Hispanic almuer- 
zolalmoço 'Lunch', with Special Attention to Older Spanish yantar/Ptg. jantar 'Dinner'" RPh, 36 (1983), núm. 4, 393-403.

- "Para el marco histórico de comborçalcombrueça "concubina", en Homenaje a Don Álvaro Galmés de Fuentes, Gredos, Madrid y Universidad de Oviedo, 1985, t. 1, pp. 245-264.

Menéndez Pidal, Ramón. La leyenda de los Infantes de Lara, Imprenta de los Hijos de J. M. Ducazcal, Madrid, 1896. (Obra premiada por la Real Academia de la Historia en 1897.) $2^{\text {a }}$ ed., ampliada; Madrid, 1934 ( = Obras: Centro de Estudios Históricos, t. 1).

- Crónicas generales de España, con láminas hechas sobre fotografías del Conde de Bernar, Establecimiento tipográfico de los Sucesores de Rivadeneyra, Madrid, 1898.

- Manual elemental de gramática histórica española, Victoriano Suárez, Madrid, 1904; 2a ed. (rev.), 1905.

- (ed.) Documentos lingüísticos de España, t. 1: Reino de Castilla, Centro de Estudios Históricos, Madrid, 1919 [-21].

MEYer [-LüBKE], W. Reseña de Horning [1883], LGRPh, 5 (1884), 277-280.

. "Die lateinische Sprache in den romanischen Ländern', en G. Gröber (ed.), Grundriss der romanischen Philologie, K. J. Trübner, Strassburg, 1888, t. 1, pp. 351-382.

- Grammatik der romanischen Sprachen, t. 1: Romanische Lautlehre, Fues/Reisland, Leipzig, 1890.

- Reseña de Ford [1900], LGRPh, 22 (1901), cois. 297 ss. 1905. "Zur Geschichte des C vor hellen Vokalen", en Bausteine zur romanischen Philologie; Festgabe für Adolfo Mussafia, Niemeyer, Halle, 1905, pp. 313-320.

MichaËlis [de Vasconcelos], Carolina. Studien zur romanischen Wortschöpfung, F. A. Brockhaus, Leipzig, 1876.

Migliorini, BRUNO. "L'intacco della velare nelle parlate romanze", en Silloge linguistica dedicata alla memoria di Graziadio Isaia Ascoli nel primo centenario della nascità, G. Chiantore, Torino, 1929, pp. 271-301 (= Archivio Glottologico Italiano, 32-33).

Monaci, ERnesto, y F. D'Ovidio. Spagnolo: grammatica e crestomazia, Manualetti d'introduzione agli studi neolatini..., Napoli, 1879.

Morf, HeINRICH (ed.). "El poema de José.", nach der Handschrift der Madrider Nationalbibliothek, Druck von W. Drugulin, Leipzig, 1883.

MúgicA, Pedro de. Gramática del castellano antiguo, t. 1: Fonética, O. R. Reisland, Leipzig y Heinrich \& Kemke, Berlin, 1891.

Mussafia, A[DOLFO]. "Osservazioni sulla fonologia francese", Ro, 18 (1889), 529-550; artículo seguido de una jugosa "Note additionnelle" de G[ASTON] P[ARIS], pp. 550-552.

Nebrija, Elio Antonio De. Gramática castellana, Salamanca, 1492. Reimpresión del incunable, con un prefacio de E. Walberg, M. Niemeyer, Halle, 1909. Texto establecido sobre $1^{\text {a }}$ ed. “princeps"'... 
por Pascual Galindo Romeo y Luis Ortiz Muñoz, Junta del Centenario, Madrid, 1946, 2 ts.

- Reglas de orthographía en la lengua castellana. 1517, ed. Ignacio González Llubera, Oxford University Press, London-New York, 1926.

Neumann, Fritz. Zur Laut- und Flexionslehre des Altfranzösischen, hauptsächlich aus pikardischen Mundarten von Vermandois. Gebrüder Henninger, Heilbronn, 1878.

PARIS, GASTON. "Note additionnelle" (1889). Véase bajo Mussafia.

- "L'altération romane du C latin", en Annuaire de l'École des hautes études (1893), 7-37. Reimpreso en: G. P., Mélanges linguistiques (ed. Mario Roques): Latin vulgaire et langues romanes, Paris, 1909, pp. 78-102.

. Comptes rendus des séances de l'Académie des Inscriptions et BellesLettres, 4-21 (1893), 81-94. Reimpreso en: G. P., Mélanges linguistiques: Latin vulgaire et langues romanes, Paris, 1909, pp. 103-114.

- Reseña de Menéndez Pidal, La leyenda de los Infantes de Lara (1896), en $J d S$, mayo y junio de 1898, pp. 296-309, 321-335, así como en $\operatorname{Rev} P, 6$ (1898), 372-395; reimpreso varias veces y traducido al español.

Paz y Melia, Antonio (ed.). Opúsculos literarios de los siglos xiv a xvi, Sociedad de Bibliófilos Españoles, Madrid, 1892, t. 29.

ReinhardstoetTner, Carl von. Grammatik der portugiesischen Sprache auf Grundlage des Lateinischen und der romanischen Sprachvergleichung, K. J. Trübner, Strassburg, 1878.

Schuchardt, Hugo. Der Vokalismus des Vulgärlateins, Teubner, Leipzig, 1866-68, 3 ts.

. Reseña de G. Paris [1893], LGRPh, 14 (1893), 360-363.

Silva Corvalán, Carmen. "La interacción de variables sociales y fonológicas [en Chile]"' (ponencia inédita), 1982.

SubaK, J. 'Zum Judenspanischer [von Konstantinopel und Bosnien]', ZRPh, 30 (1906), 129-185.

Tallgren[-TuUlio], Oiva Joh[AnNes]. "Las $z$ y $\varsigma$ del antiguo castellano iniciales de sílaba, estudiadas en la inédita Gaya[ciencia] de [Pero Guillén de] Segovia", en Mémoires de la Société Néo-philologique à Helsingfors, t. 4 (Paris-Helsingfors-Leipzig, 1905-06), pp. 1-50, 397-401 ("Adiciones y correcciones").

— . Estudios sobre la Gaya [ciencia] de [Pero Guillén de] Segovia; capítulos de introducción a una edición crítica, disertación, Univ. de Helsingfors, Helsinki, 1907.

- y J. M. Casas Homs, ed. crítica de Pero Guillén De SEgoVIA, La gaya ciencia, transcripción, introducción, vocabulario e índices, C.S.I.C., Madrid, 1962, 2 ts.

Verner, CARL. "Eine Ausnahme der ersten Lautverschiebung", Zeitschrift für vergleischende Sprachforschung, 23 (1875-76), 97-130.

VOLlMöller, Karl GuSTaV (ed.), Ein [alt]spanisches Steinbuch, mit Einkitung und Ammorkungen, Gebrüder Henninger, Heilbronn, 1880. 
WAGNER, MAX LEOPOLD. Beiträge zur Kenntnis des Judenspanischen von Konstantinopel, Kaiserliche Akademie der Wissenschaften (Linguistische Abteilung, 2:3), A. Hölder, Wien, 1914.

Zauner, Adolf. Altspanisches Elementarbuch, Niemeyer, Halle, 1908; $2^{\mathrm{a}}$ ed. (rev.), 1921. 